Published in "Biodiversity and Conservation 25(10): 1863-1877, 2016"

which should be cited to refer to this work.

\title{
Hybridization as a threat in climate relict Nuphar pumila (Nymphaeaceae)
}

\author{
Nils Arrigo $^{1}$ - Sébastien Bétrisey ${ }^{2,3}$ - Larissa Graf ${ }^{4}$. \\ Julia Bilat ${ }^{1}$ - Emanuel Gerber ${ }^{2}$ Gregor Kozlowski ${ }^{2,3}$
}

\begin{abstract}
Field studies and conceptual work on hybridization-mediated extinction risk in climate relicts are extremely rare. Nuphar pumila (Nymphaeaceae) is one of the most emblematic climate relicts in Europe with few isolated populations in the Alpine arc. The extent of introgression with related lowland and generalist species Nuphar lutea has never been studied using molecular methods. All biogeographical regions where N. pumila naturally occurs in the neighbourhood of the Alpine arc were sampled and studied using nuclear microsatellite markers. Furthermore, we used forward-in-time simulations and Approximate Bayesian Computation to check whether an introgression scenario fits with the observed admixture patterns and estimated the demographic parameters associated with this process. Our study confirms ongoing hybridization between N. pumila and N. lutea and validates it by the use of population models. More than $40 \%$ of investigated N. pumila individuals were admixed and hybrids were found in over $60 \%$ of studied populations. The introgression is bidirectional and is most likely a result of very recent gene flow. Our work provides strong evidence for rapid extinction risk and demographic swamping between specialized climatic relicts and closely related generalists. The remaining pure populations of $N$. pumila are rare in the Alpine arc and deserve high conservation priority.
\end{abstract}

Electronic supplementary material

$\triangle$ Gregor Kozlowski

gregor.kozlowski@unifr.ch

1 Department of Ecology and Evolution, University of Lausanne, Biophore Building, 1015 Lausanne, Switzerland

2 Natural History Museum of Fribourg, Chemin du Musée 6, 1700 Fribourg, Switzerland

3 Department of Biology and Botanical Garden, University of Fribourg, Chemin du Musée 10, 1700 Fribourg, Switzerland

4 Kantonsschule Wattwil, Näppisuelistrasse 11, 9630 Wattwil, Switzerland 
Keywords Boreal geoelement · Hybridization-mediated extinction · Introgression · Nuphar lutea $\cdot$ Nuphar pumila $\cdot$ Refugia

\section{Introduction}

Natural hybridization plays a fundamental role in the evolution of many organisms (Rieseberg 1997, 2000; Barton 2001; Hegarty and Hiscock 2005; Chapman and Burke 2007). It is especially frequent in plants; $10-12 \%$ of extant species are involved in ongoing hybridization/introgression processes or have a hybrid origin (Mallet 2007; Whitney et al. 2010). However, hybridization and introgression can have harmful effects on the progeny's fate. In rare and endangered species, it can increase the threat of extinction, mainly due to genetic swamping with a common relative where genetic distinctiveness might disappear (Levin et al. 1996; López-Caamal et al. 2014; Todesco et al. 2016). Although the risk of extinction through hybridization has attracted attention for several decades, most researchers have focused on the spread of non-native and invasive species and their impacts on endangered indigenous taxa (Rhymer and Simberloff 1996; Vilà et al. 2000; Wolf et al. 2001; Muhlfeld et al. 2014). Little attention has been given to the effects of hybridization between native, widespread species and their closely related but rare and threatened relatives (Garroway et al. 2010; Kabátova et al. 2014; Balao et al. 2015).

Climate relicts are remnants of past populations that have become fragmented by climate-driven changes in the environment and habitat loss-they were left behind during past range shifts and may persist today only in enclaves of benign environmental conditions within an otherwise inhospitable regional climate (Hampe and Jump 2011; Woolbright et al. 2014). However, field studies and conceptual work on hybridization-mediated extinction risk in climate relicts are extremely rare (Brown 1971; Thórsson et al. 2010; Nierbauer et al. 2014). This lack of studies is surprising because, due to global warming, widespread species tend to shift their latitudinal and altitudinal distributions and more often come into contact with rare and endemic taxa (Theurillat and Guisan 2001; Engler et al. 2011). It is only recently that researchers have begun to investigate the consequences of such human-driven hybridization events. One of the most dramatic consequences appeared as the hybridization-mediated "silent extinction" of rare and endemic highmountain plants (Gómez et al. 2015) and climate relicts (Hampe and Jump 2011).

Here, we investigate Nuphar pumila, one of the most emblematic climate relicts with only few isolated populations in the Alps and neighboring mountain systems (HeslopHarrison 1955; Meusel et al. 1965; Roweck 1988). N. pumila shares a common ancestor with the widespread lowland species Nuphar lutea, and both taxa form a fertile hybrid, named Nuphar $\times$ spenneriana Gaudin (Padgett et al. 1999; Roweck and Reinöhl 1986; Roweck 1988), that usually occurs in areas where the distributions of both parental species overlap (Heslop-Harrison 1953, 1955). The hybrid Nuphar $\times$ intermedia is diploid and has the same chromosome number $(2 \mathrm{n}=34)$ as both parental species and all other Nuphar spp. (Fedorov 1974; Padgett 2007). Although hybridization seems to be common among Nuphar species (Padgett et al. 1998, 2002; Shiga and Kadono 2007, 2008) and has been notably documented in North America (Nuphar $\times$ rubrodisca, resulting from Nuphar microphylla $\times$ Nuphar variegata) and Japan (Nuphar $\times$ saijoensis, from Nuphar japonica 
$\times N$. pumila), many of these hybrids have not been studied in any detail, especially at the genetic level.

In our study, we aimed to address the following questions: (i) Can the hybridization between $N$. pumila and $N$. lutea in the Alpine arc be confirmed using molecular methods? (ii) If so, what is the magnitude of the hybridization? (iii) Is the introgressive hybridization uni- or bidirectional? (iv) Is the hybridization between the two taxa recent or rather an ancient phenomenon, and what might be the pace of the hybridization process? More generally, based on obtained results and population models, we aimed to explore the processes behind the observed pattern and to discuss whether hybridization represents an important threat for climatic relicts in general, especially in the context of global change in alpine ecosystems.

\section{Methods}

\section{Study species}

The genus Nuphar (Nymphaeaceae), with its 10-15 species, is a conspicuous component of the freshwater flora throughout most of the Northern Hemisphere (Padgett 1998, 2007; Padgett et al. 1999; Preston and Croft 2001). The least water-lily (N. pumila (Tiмm.) DC) and the yellow water-lily ( N. lutea L.), are the only European species in the genus (Padgett 2007). For more details on ecological and morphological differences between the specialist $N$. pumila and widespread generalist $N$. lutea see Online Resources 2 and 6.

Nuphar pumila is a typical climate relict with only few isolated populations surviving in central Europe, the Alps and neighbouring mountain systems (Heslop-Harrison 1955; Meusel et al. 1965; Roweck 1988). The main distribution area stretches between Northern Europe and eastwards through central and southern Russia to Manchuria and probably Japan. The European representatives belong to the typical subspecies (subsp. pumila) (Heslop-Harrison 1955; Meusel et al. 1965; Dezhi and Padgett 2001; Padgett 2007). In the Alps it has been described from very scattered localities in Switzerland (Northern Alps), Austria (Kärnten, Tirol) and Germany (Bavaria and eastern Baden-Württemberg). Additionally, some isolated populations exist in the Black Forest (Schwarzwald) in Germany as well as in the Jura, Vosges and Massif Central in France (Käsermann and Moser 1999). Moreover, there are highly isolated populations in Spain (Cantabria) and in the Balkan Peninsula (Meusel et al. 1965; Lozano et al. 2008). In such southern regions the species is always confined to alpine and mountainous regions.

Nuphar pumila is a specialist species restricted to mountain lakes with relatively shallow banks (0.5-2.0 $\mathrm{m}$ of depth) and rather acid waters. The species neither occurs in flowing waters nor in waters exposed to strong wind action (Heslop-Harrison 1955). The species occurs in floating leaf communities. In Central Europe it is described as a postglacial relict and is a characteristic species of its own relict association Nupharetum pumili (Oberdorfer 1977). Together with N. microphylla from North America it belongs to socalled Nuphar-dwarfs since they are much smaller in size and number of floral parts than the most common species N. lutea (Heslop-Harrison 1955; Meusel et al. 1965; Padgett 1998, 2007). Most information on N. pumila in the Alps and surrounding area could be found in the publications of Kozlowski and Eggenberg (2005); Roweck and Reinöhl (1986); and Roweck (1988). Finally, the papers of Heslop-Harrison $(1953,1955)$ on the 
genus Nuphar in Great Britain, although published more than half a century ago, remain valuable.

\section{Population sampling}

Our sampling covered the entire species distribution in the Alps and neighbouring mountain ranges. It included all existing populations from Switzerland and Austria, as well as selected populations from all mountain ranges where both species occur naturally in France (Jura, Vosges) and Southern Germany (Black Forest, Eastern Baden-Württemberg and Bavaria). Importantly, three populations (JON, GRA and HAL) occurred in ponds and lakes of high altitude; where the presence of $N$. lutea - a lowland species-has never been attested. Those three populations have been used as reservoirs of "pure N. pumila" genotypes for recent ex situ collections and re-introduction campaigns (Kozlowski and Eggenberg 2005) and were considered as the $N$. pumila reference pool in our analyses. Collections were made in 2014 at the height of the growing season (June/August). Leaves were washed thoroughly in water, dried with paper towels and stored in plastic bags with silica gel (Chase and Hills 1991). Altogether thirteen natural populations of $N$. pumila were sampled and leaf material was retrieved from 4 to 28 individuals per population for a total of 194 individuals (Table 1). From large populations, minimum 15 individuals and from very small populations all individuals were sampled. Additionally, 20 individuals of $N$. lutea from two natural populations and one botanic garden were sampled (Table 1). All voucher specimens (one individual per population) were deposited in the herbarium of the Natural History Museum Fribourg, Switzerland (NHMF).

\section{DNA extractions and SSR genotyping}

DNA was extracted from 10 to $12 \mathrm{mg}$ of silica-gel dried leaves, using an automated extraction robot (Biosprint, Qiagen, Hilden, Germany) and following manufacturer's instructions. DNA qualities and concentrations were evaluated with agarose gels and nanodrop. A total of eight fluorescently labeled nuclear SSR loci were selected (NLGA2, NLGA3, NLGA5, NLGA7, NLCA1, NLTG/GA1, Nsub033 and Nsub176) after a preliminary screening for marker transferability, polymorphism and reproducibility, using published primers (Ouborg et al. 2000; Yokogawa et al. 2012). Amplifications were carried out in $10 \mu \mathrm{l}$ reaction volumes containing $1 \times$ GoTaq Flexi Buffer (Promega, Madison, WI, USA), $2 \mathrm{mM} \mathrm{MgCl} 2$ (Promega), $200 \mu \mathrm{M}$ of each dNTP (Promega), $500 \mathrm{ng} / \mu \mathrm{l}$ of Beaf Serum Albumin (Promega), $0.2 \mu \mathrm{M}$ of forward and reverse primer (Microsynth AG, Balgach, Switzerland), $0.03 \mathrm{U} / \mu \mathrm{l}$ of Taq polymerase (Promega) and $2 \mu \mathrm{l}$ of genomic DNA. PCRs were performed on Tgradient thermocyclers (Biometra, Goettingen, Germany) according to the following program: $1 \mathrm{~min}$ at $94{ }^{\circ} \mathrm{C}$, followed by 35 cycles of: $30 \mathrm{~s}$ at $94{ }^{\circ} \mathrm{C}, 30 \mathrm{~s}$ at 52,55 or $57{ }^{\circ} \mathrm{C}$ (see Online Resource 1 for marker details) and $35 \mathrm{~s} 72{ }^{\circ} \mathrm{C}$ with a final elongation of $15 \mathrm{~min}$ at $72{ }^{\circ} \mathrm{C}$. Marker-specific adjustments involving annealing condition, PCR temperature ramps and dilutions of genomic DNA were also necessary to obtain optimal amplifications (see Online Resource 1 for further details). Between 1 and $6 \mu \mathrm{l}$ of PCR amplifications were pooled, along with an internal size standard (Gene Scan-500 ROX; Applied Biosystems, Foster City, CA, USA), to produce two multiplex mixes. The genotyping was performed on an ABI 3100 automatic sequencer and allele scoring was relied on visual inspection of electropherograms with GeneMapper V 4.0 (Applied Biosystems). The reproducibility of results was assessed by replicating 


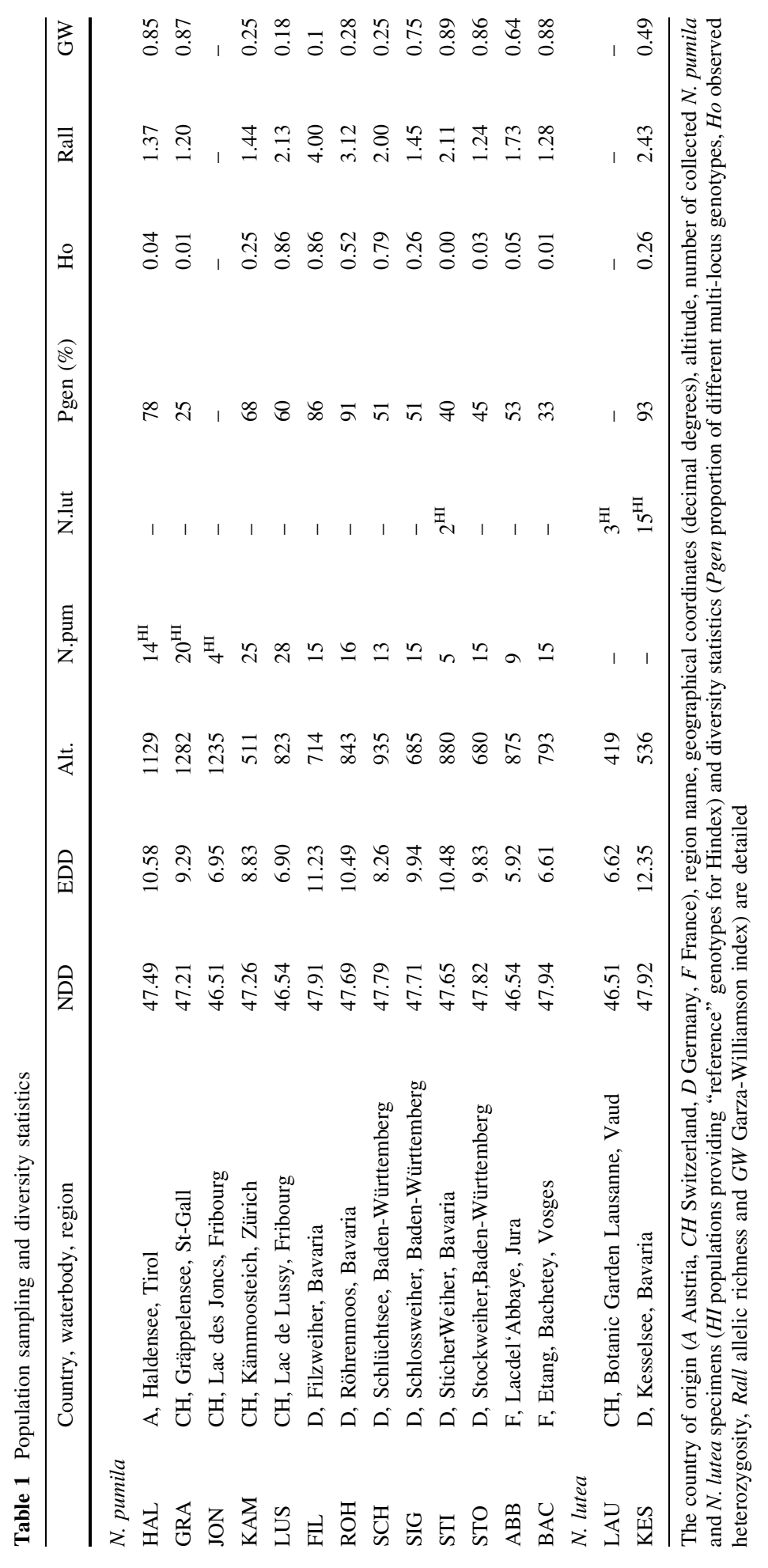


one sample chosen randomly within each population (representing $7 \%$ of the final data set).

\section{Genetic diversity and principal component analysis}

Four diversity metrics were estimated for each population: the proportion of different multi-locus genotypes (Pgen), observed heterozygosity (Ho), allelic richness (Rall, as the average number of alleles observed per locus) and the Garza-Williamson index ( $G W$, defined as Rall divided by the range of SSR allele sizes). These estimates were obtained as multi-locus averages, using a rarefaction procedure accounting for unequal sampling efforts among populations (diversity metrics were computed from the repeated resampling of five specimens per population, using R CRAN scripts from Delplancke et al. 2012). All markers produced co-dominant genotypes bearing one to two alleles, except for NLGA7 where three to four alleles per specimen were observed in several populations (suggesting population-specific duplications). This locus was nevertheless retained to estimate Pgen, Rall and GW-as it was relevant to these metrics-but was excluded from $\mathrm{Ho}$ estimations.

Genetic differentiation patterns among species and specimens were investigated using a principal component analysis (PCA). Briefly, this approach places each specimen within a summary space of eigenaxes that captures at best the genetic variation structuring our SSR dataset. Importantly, we assumed a Step Mutation Model (i.e. "SMM", where allelic mutations are associated to size variations, Neuenschwander et al. 2008), by recoding our dataset of SSR multi-locus genotypes into a presence-absence matrix weighted by allelic sizes ( $R$ scripts available upon request). As a result, the placement of specimens in the PCA informs not only about allelic compositions (as obtained with an Infinite Allele Model, see Online Resources 4-5) but also on allelic size differences. Our analysis thus better accounts for genetic mutations and thus efficiently discriminates Nuphar species from one another.

\section{Estimation of genetic admixture}

We investigated admixture patterns using Hindex V 1.42 (Buerkle 2005). Briefly, two "reference" groups of specimens -providing representative allele frequencies for each species-are used to estimate the admixture level (hereafter Hindex) of another set of specimens that are of putative hybrid origin. The reference specimens were selected from the GRA, JON and HAL populations for $N$. pumila, owing to the absence of $N$. lutea genotypes (and alleles) reported from those high altitude ponds. The reference genotypes of $N$. lutea were obtained from a natural population (KES) and a botanical garden. As a result, each specimen gets a Hindex value proportional to its content in $N$. lutea alleles that ranges between 0 ("pure" N. pumila) and 1 ("pure" N. lutea), first generation hybrids yield a Hindex of 0.5 , while admixed genotypes trend to 0 or 1 , according to which species acted as the recurrent backcrossing parent. This tool proves robust to Hardy-Weinberg deviations and is suitable for the analysis of species potentially reproducing clonaly. Also, this approach accommodates mixtures of markers types, allowing the use of all the investigated SSR loci (that were treated as co-dominant, except NLGA7 being recoded as allelic presences/absences and declared as dominant).

The Hindex value informs about the respective contributions of N. pumila and N. lutea to the genomes of hybrid specimens. As such, it appropriately tracks an introgression process driven mostly by recurrent backcrosses (since the genomic composition of the introgressant genotypes changes from a generation to the next, via the production of 
$\mathrm{BC} 1 \mathrm{~s}, \mathrm{BC} 2 \mathrm{~s}$, etc.). However, the Hindex has limited power to explore segregation patterns within purely hybrid populations (i.e. those leading to the production of F2 s, F3s, etc.). Under such a dynamic, early and late generation hybrids yield similar Hindex values, centered around 0.5). We thus explored another important dimension of genetic admixture-inter-specific heterozygosity-defined as the proportion of heterozygous loci showing alleles of distinct parental species origin. This metric is expected to decrease during the successive generations of hybridization, owing to the random fixation of parental alleles within the hybrid population (Fitzpatrick 2012). Although several implementations are available to estimate inter-specific heterozygosity, most of those assume independent loci (e.g. Hiest, Fitzpatrick 2012) and do not apply to species potentially reproducing clonally. Instead, we used the large SSR allele size differences observed between $N$. pumila and $N$. lutea to identify heterozygous loci that were putatively of interspecific origin. For a heterozygous individual, with genotype $A a$ at locus $A$, we computed $\Delta S S R_{a}=(A-a) /\left(A_{\max }-A_{\min }\right)$, where $A_{\max }$ and $A_{\min }$ are the largest and smallest allele sizes observed for the focal locus. We then computed $\triangle S S R$, as the average SSR allele size differences observed across all loci, and for each specimen. This metric thus ranges from 0 (i.e. fully homozygous specimen) to 1 (fully heterozygous specimen, showing maximal allele size differences).

\section{Simulations and approximate bayesian computation}

We used forward-in-time simulations and Approximate Bayesian Computation (hereafter $\mathrm{ABC}$ ) to (i) check whether an introgression scenario fits with the observed admixture patterns and (ii) estimate the demographic parameters associated to this process. The complete ABC pipeline was built upon R scripts developed in Pajkovic et al. (2014) and relied on QuantiNEMO V 1.6.0 (Neuenschwander et al. 2008). Further details and corresponding $\mathrm{R}$ scripts are available on Dryad (doi:10.5061/dryad.8f0d4).

We considered an island model where a large $N$. lutea pool acted as a source of alleles emigrating towards the $13 \mathrm{~N}$. pumila populations (the parameter $M_{l u t-p u l}$ controlled the proportion of migrants leaving the $N$. lutea and pool and entering the $N$. pumila metapopulation, at each generation). Each $N$. pumila population received immigrants with the same probability during a given number of generations (parameter $T_{g e n}$ ); migrations from $N$. pumila towards the $N$. lutea pool were not allowed but exchanges among $N$. pumila populations could occur according to the $M_{\text {pul-pul }}$ parameter (i.e. proportion of specimens leaving each $N$. pumila population). The carrying capacity of each population (i.e. census size) was drawn from a Poisson distribution (with an average defined via the $N_{\text {pum }}$ parameter). The reproductive biology of Nuphar species was modelled by controlling for the proportion of offsprings produced via clonal versus sexual reproduction (parameter $C_{\text {Nuphar }}$ ). The simulations were based on nine codominant loci that were recoded into an allele presence/absence matrix. This strategy allowed accounting for locus duplications (as observed for NLGA7), by merging the signals of two loci as a single marker. We assumed a SMM mutation model (see above), with an average mutation rate of $1 \times 10^{-4}$ new alleles arising per meiosis event. Allelic dropouts (i.e. presence of alleles remaining undetected due to PCR amplification failure) were modelled using a Poisson distribution (with an average controlled via the $D_{\text {all }}$ parameter) determining how many "null" alleles arise at each locus. 


\section{Priors and summary statistics}

The $\mathrm{ABC}$ framework was used to explore parameter values using prior uniform distributions that were bounded as follows: $0>T_{\text {gen }} \leq 10$ (making the assumption that admixture resulted from recent introgression events); $0 \geq M_{\text {lut-pul }} \leq 0.5 ; \quad 0>M_{\text {pul-pul }} \leq 0.5$; $1>N_{\text {pum }} \leq 100 ; 0>C_{\text {Nuphar }} \leq 1$ and $0>D_{\text {all }} \leq 2$. The simulations were initiated by resampling existing genotypes within each population, after removal of admixed specimens (identified according to the Hindex values established earlier). Our simulations thus started from populations that were differentiated in a realistic way and, more importantly, that were free of any recent admixture. As a consequence, our simulations informed about the demographic regime needed to reproduce the observed admixture patterns, starting from a landscape void of hybridization. In an $\mathrm{ABC}$ framework, simulations are compared to empirical patterns using so-called "summary statistics". Following Pajkovic and colleagues (2014), we tracked the abundance of $N$. lutea alleles in each simulated N. pumila specimen, as well as specimen-level admixture levels (using fuzzy-clustering cmeans, a fast and suitable approximation of Hindex). These metrics were summarized into population-level averages and standard deviations, resulting in 42 summary statistics recorded per simulation (i.e. 13 populations investigated, each with two admixture estimates, and summarized with mean and standard deviation). The same summary statistics were also recorded for the empirical dataset.

\section{Model selection and parameter estimates}

First, we tested whether an introgression scenario (i.e. $M_{l u t-p u l} \geq 0$ ) best approximated the empirical patterns compared to a null model assuming the absence of gene flow (i.e. $M_{\text {lut }}$ $p u l=0$ ). To this end, (i) we produced 500,000 simulations under each scenario, (ii) pooled them, (iii) extracted the 1000 simulations minimizing euclidean distances to the empirical summary statistics and (iv) quantified the respective contributions of each model to the pool of best simulations. A cross-validation approach was then applied to estimate the probability of accepting the wrong model under the obtained results. Next, model parameters were estimated by considering the 1000 best simulations, out of a total of $3,500,000$. The obtained posterior distributions were refined using neural net local adjustments, as implemented in the abc R package (Csilléry et al. 2012, using logit transformation and 50 iterations for the neural net). The consistency of estimations was evaluated using a cross-validation procedure. All simulations were performed on the VitalIT High-Performance Computing Center (Swiss Institute of Bioinformatics).

\section{Results}

\section{Genetic diversity}

A total of 84 fully-reproducible alleles were detected, with each SSR locus contributing between 6 (Nsub033) and 15 (NLGA7) alleles. These markers allowed discriminating 90 distinct multi-locus genotypes among the 214 analyzed specimens (i.e. $42 \%$ of our sampling effort); 75 (39\%) distinct multi-locus genotypes were observed in N. pumila only. 
Overall, populations showed contrasted diversity levels (Table 1); six populations were characterized by low diversities (i.e. ABB, BAC, GRA, STI, STO and HAL; except for the Pgen metric), while the others (i.e. FIL, KAM, LUS, ROH, SCH, SIG) had notably high Pgen, $\mathrm{Ho}$ and Rall values. Importantly, the majority of these diversified populations showed $G W$ values indicative of large allele size variations.

\section{Principal component analysis and hindex}

Nuphar lutea and Nuphar pumila differed markedly in terms of allelic sizes; a pattern that was captured by the first eigenaxis of our PCA. As a result, inter-specific differentiation accounted for $59 \%$ of the total genetic variance of our SSR dataset (Fig. 1a). Several specimens, recognized as $N$. pumila using morphologic characters, appeared as admixed and amplified alleles typical of $N$. lutea. This pattern was clearly evidenced via the PCA and Hindex metric, where admixed genotypes delineated a complete introgressive serie between the two species. In terms of putative inter-specific heterozygosity, all admixed specimens showed large heterozygosity levels, characterized by large allele sizes differences (Fig. 1b).

Most admixed specimens were observed in populations characterized by high genetic diversities and low GW values (Fig. 2; FIL, KAM, LUS, ROH, STI and SCH). To this respect, FIL, LUS and SCH were of particular interest as they were dominated by admixed genotypes.
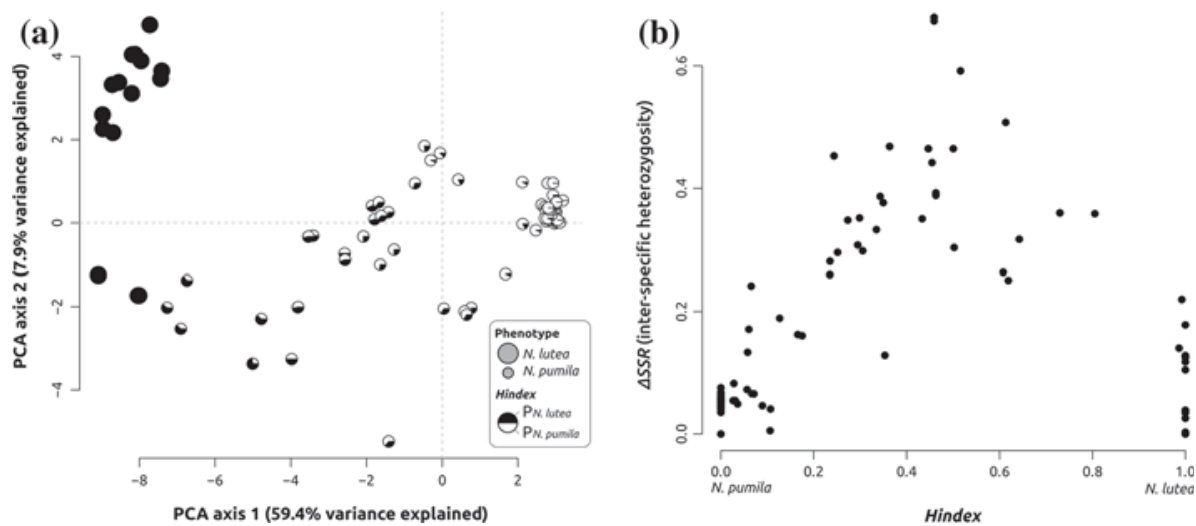

Fig. 1 a Principal coordinates analysis of individual genotypes. Our sampling includes 194 N. pumila specimens (small pie charts) collected in 13 natural populations, completed with $20 \mathrm{~N}$. lutea specimens (large pie charts) from natural populations (KES-15 specimens, STI-2 specimens) and botanical gardens (LAU-3 specimens). Distances among specimens are computed according to their genotype, as characterized by 8 SSR loci, and accounting for differences in allele sizes. In parallel, we display the admixture levels of specimens, estimated with the Hindex value (Buerkle 2005), using pie-charts. Every specimen is assigned either to N. lutea (black) or N. pumila (white) genetic pool using a probabilistic framework; pure breed specimens receive a probability of 0 ( $N$. lutea) or 1 ( $N$. pumila) while first generation hybrids and further admixed genotypes get intermediate probabilities. b Hybrid index and putative inters-specific heterozygosity. We display each analyzed specimen according to its respective Hindex and $\triangle S S R$ values. Those metrics inform about important dimensions of the admixture process. As explained above, Hindex estimates the respective contribution of $N$. pumila vs. $N$. lutea alleles to each genotype. $\triangle S S R$ is a proxy for interspecific heterozygosity (measured here as relative SSR allele size differences across heterozygous loci), and rather informs about the timing of hybridization (i.e. with high and low $\triangle S S R$ values being expected for early and late generation hybrids, respectively) 


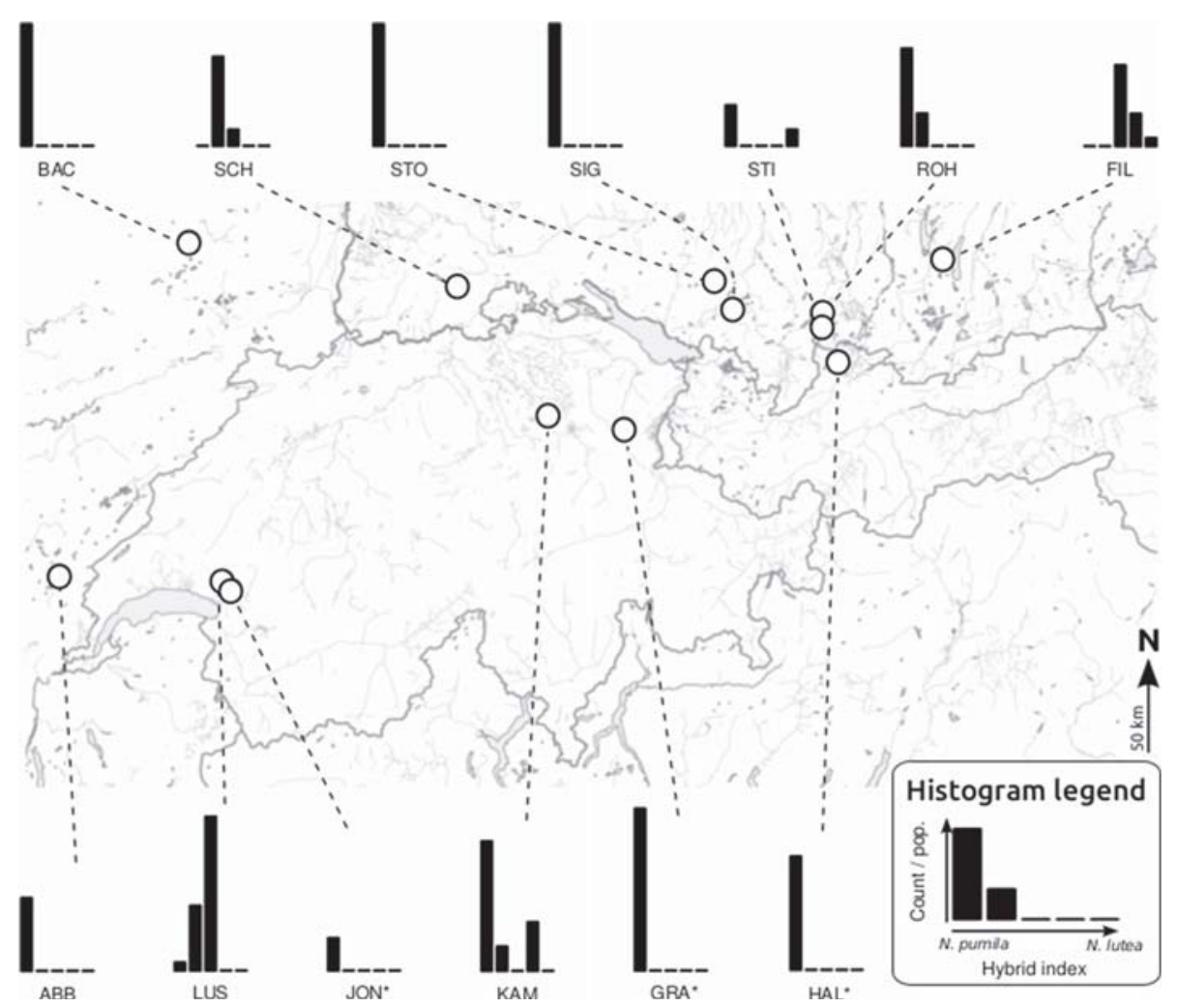

Fig. 2 Sampling area and admixture levels between N. pumila and N. lutea. The geographic location and the proportions of pure breed versus hybrid genotypes is indicated for the 13 surveyed populations. Briefly, each specimen is assigned either to $N$. lutea or $N$. pumila gene pools, based on its 8 loci SSR genotype, using the hybrid index (Buerkle 2005). The obtained assignment probabilities $\left(\mathrm{P}_{\text {pumila }}\right.$ and $\left.\mathrm{P}_{\text {lutea }}\right)$ are directly proportional to admixture levels (see Fig. 1) and are summarized throughout the surveyed populations using histograms (considering five admixture categories, ranging from $\mathrm{P}_{\text {pumila }}=0.00$ to 1.00 ). The "reference" genotypes for $N$. pumila, used for estimating Hindex were collected in populations marked with asterisks

\section{Approximate Bayesian Computing}

The model accounting for inter-specific introgression best explained our empirical results and yielded $86 \%$ of posterior probability ( $p$ value $=0.03$, online resources $4-5$ ). Parameter estimates (Fig. 3) suggested ongoing gene flow with $M_{\text {lut-pul }}=230 \mathrm{~N}$. lutea immigrants recurrently entering into the $N$. pumila metapopulation (HPD95 $=85-397$ ) over the last $T_{\text {gen }}=4$ generations (HPD95 $=1.83-4.57$ ). The populations appeared as small with an average carrying capacity of $N_{\text {pum }}=21$ individuals (HPD95 = 12.43-46.80). The overall clonal rate was of $C_{\text {Nuphar }}=0.31 \quad($ HPD95 $=0.13-0.54)$. Migration events among $N$. pumila populations and allelic dropout were estimated at $M_{\text {pul- }}$ ${ }_{p u l}=0.15(\mathrm{HPD} 95=0.05-0.35)$ and $D_{\text {all }}=1.48$ (HPD95 $\left.=0.53-1.98\right)$, respectively.

These estimations must however be considered within the statistical limits of our model. Accordingly, cross-validations confirmed the presence of large confidence intervals and, importantly, showed that several parameters were most likely overestimated (Online Resources 3-5). Accordingly, correcting for these systematic biases yielded the following 
(a)

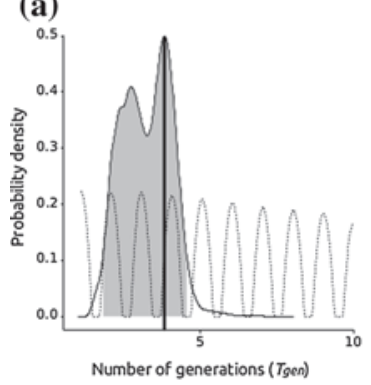

(d)

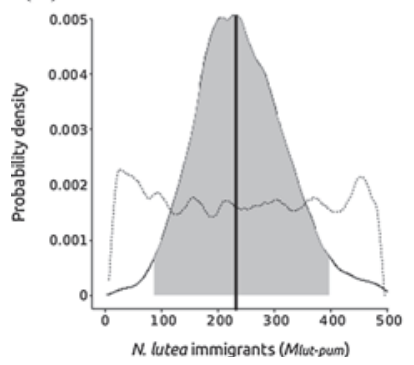

(b)

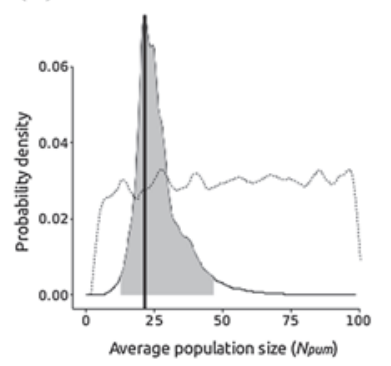

(e)

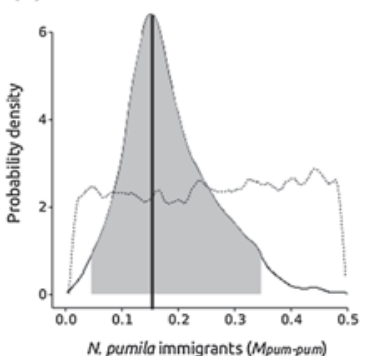

(c)

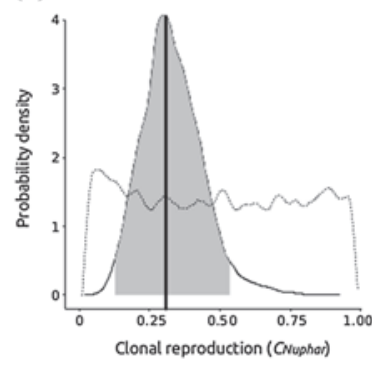

(f)

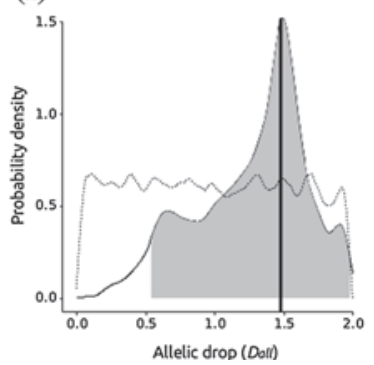

Fig. 3 ABC posterior distributions. Model parameters were estimated using an $A B C$ pipeline adapted from Pajkovic et al. (2014). These estimations are based on 1000 simulations that approximated best the observed empirical patterns (solid line-posterior distribution, shaded area-95\% Highest Posterior Density credibility interval, vertical bold line - distribution mode), out of 3,500,000 simulations that explored the complete model parameter space using Uniform prior distributions (dashed lines)

estimates: $T_{\text {gen }}=3, N_{\text {pum }}=6, M_{\text {lut } \text { pul }}=170$ and $C_{\text {Nuphar }}=0.16$. Finally, cross-validations outlined that our model and $\mathrm{ABC}$ procedure produced essentially random and uninformative estimations for the $M_{p u l-p u l}$ and $D_{\text {all }}$ parameters (Online Resources 4-5).

\section{Discussion}

Our study confirms ongoing hybridization between $N$. pumila and $N$. lutea and validates it using population models. More than $40 \%$ of investigated $N$. pumila individuals were admixed and hybrids were found in over $60 \%$ of studied populations. The introgression is bidirectional (although not directly monitored within $N$. lutea populations, our results nevertheless show that this species can act as the recurring parent of back-crosses) and is most likely a result of very recent gene flow (as suggested by large levels of putative interspecific heterozygosity and the direct estimation of generation times using $A B C$ ). Our work provides strong evidence for rapid extinction risk and demographic swamping between specialized climatic relicts and closely related generalists.

Thus, our molecular survey confirms the highly vulnerable and endangered status of the relictual populations of $N$. pumila in the Alpine area. Several recent studies outlined the rapid decay of this species, with almost 20 stations that went extinct in Switzerland over the last century following human-mediated landscape alterations (Kozlowski and Eggenberg 2005). Consistent with these observations, our survey reveals alarmingly low diversity 
levels in the vast majority of those surviving populations (Table 1) and, more importantly, that hybridization with $N$. lutea is widespread among both species and prone to further threaten the remaining populations of $N$. pumila (Figs. 1, 2).

Although hybridization might be considered of interest for conservation purposes (e.g. Becker et al. 2013; Garnett et al. 2011), the admixed genotypes we observed rather correspond to an introgression process. Contrasting with hybrid-driven speciation events (i.e. allopolyploid or homoploid hybrid species-where hybridization gives rise to lineages that are reproductively and ecologically isolated from their ancestors), the hybrids we observed here keep back-crossing with their parental species and therefore essentially fuel an introgression process. As a result, the expanding $N$. lutea will most likely exclude the resident populations via competition and genetic swamping. Over the long term, it is likely that the only traces left by $N$. pumila will subsist as nuclear or cytoplasmic alleles introgressed within the expanding $N$. lutea populations (i.e. signatures of secondary contacts, see examples in Excoffier et al. 2009; Arrigo et al. 2011; Alcala et al. 2013).

Interestingly, in certain countries conservation efforts are devoted to some spontaneous and rare Nuphar hybrids (e.g. in Japan for the endemic $N . \times$ saijoensis, Padgett et al. 2002). In Europe such initiatives could be justified only in regions where pure $N$. pumila does not exist anymore, e.g. in some regions of Great Britain or in the Black Forest in south Germany (Roweck 1988; Heslop-Harrison 1953; Kozlowski and Eggenberg 2005).

The spread of $N$. lutea can be better understood by comparing the morphology and ecology of both species (Online Resources 2 and 6). N. pumila is smaller in size of floral and vegetative parts and is a typical specialist of cold, stagnant and shallow water bodies (Heslop-Harrison 1955; Kozlowski and Eggenberg 2005). The ecological amplitude of $N$. lutea is much wider and thus this generalist species shows competitive superiority.

Using an $\mathrm{ABC}$ approach, we explored the dynamics of this demographic process and estimated its key parameters. We confirmed that most surviving populations had very small census sizes and that clonal reproduction accounted for an appreciable fraction of the produced off-springs. These results were consistent with the low diversity levels observed earlier and further outlined the vulnerability of $N$. pumila. In terms of hybridization, our model suggested that $N$. lutea alleles were flowing readily within the $N$. pumila metapopulation, and that the number of immigrants $\left(M_{l u t-p u l}=170\right)$ might well exceed the actual resident population (with $N_{\text {pum }}=6$ as the average carrying capacity, the complete set of surveyed populations is predicted to contain $78 \pm 8$ specimens in total) during recent times. Although these results should be considered within the statistical limits of our model (see below), the obtained estimates are consistent with the frequent presence and recent spread of $N$. lutea in the European landscape. It should also be noted that this species is of horticultural interest and has been introduced in many artificial ponds in Europe.

\section{Model and sampling limitations}

Our model necessarily relied on simplifying assumptions that could have impacted our estimates. More particularly, Nuphar species are long-lived organisms that grow for 3-4 years to reach an adult and flowering stage (Heslop-Harrison 1955). From there, the flowering occurs annually, so that overlapping generations should be considered. Our model assumed an annual species, where each generation replaces that of its parents. This could lead to overestimation of the number of immigrant genotypes, as the source of $N$. lutea alleles is assumed to be replenished at each generation (in contrast with an overlapping generations scenario, where resident $N$. lutea specimens could further contribute to the introgression process). Also, clonal reproduction coupled to small populations leads to 
important drift levels that quickly erases any demographic signature; this limitation might account for the wide confidence intervals we observed. This limited statistical power might also account for discrepancies observed between population census sizes estimated using ABC (6 individuals per population on average) and those reported from our field sampling (15 putatively distinct individuals collected per pond). Those discrepancies might well reflect the difficulty of sampling distinct specimens in aquatic plants as discriminating ramets from genets remains challenging in such an environment (N.B. such sampling uncertainties were captured by our ABC model as clonal reproduction, which we believe is conservative behaviour).

\section{Conservation implications}

From this perspective, it appears clearly that $N$. pumila is on the brink of extinction, a situation further aggravated by $N$. lutea that introduces clear competitive and hybridization pressures. Thus, the remaining pure populations of $N$. pumila in the Alpine arc deserve high conservation priority. Regular monitoring by local stakeholders and strict interdiction of any introduction of $N$. lutea in the vicinity of the pure populations of $N$. pumila designated in our study should be instigated by the local administration. Special priority must be given to the populations growing at high altitudes $(>1000 \mathrm{~m}$ a.s.l.) where the lowland species $N$. lutea is not (yet) able to spread and to be maintained: in Lac des Joncs at $1235 \mathrm{~m}$ a.s.l. and in Gräppelensee at $1282 \mathrm{~m}$ a.s.l., both in Switzerland, as well as in Haldensee (1129 m a.s.1.) in Austria.

Acknowledgments We are grateful to the following persons and institutions for their precious help, collaboration and/or issue of permissions: Switzerland-Botanic Gardens of St-Gall, Zürich, Geneva, Lausanne and Fribourg; B. Clément and E. Kozlowski, Botanic Garden of the University of Fribourg; M. Achermann and F. Cheda, Service de la Nature et du paysage de l'Etat de Fribourg; A. Keel, Amt für Landschaft- und Naturschutz, Kanton Zürich; G. Ackermann, Amt für Natur Jagd und Fischerei, Abteilung Natur und Landschaft, Kanton Sankt Gallen; R. Züllig, Gemeindepräsident Gemeinde Wildhaus-Alt Sankt Johann; C. Huber, UNA, Bern; R. Heeb and Ch. Peisker, Kantonsschule Wattwil; L. Champoud and V. Kam, Collège du Sud, La Frasse; F. Genoud, Auberge du Lac des Joncs, Les Paccots; Coordination régionale pour la protection de la flore (FR-GE-NE-VD); S. Eggenberg, Info Flora; D. Vogt, Bern. France-E. Brugel, Conservatoire botanique national de Franche-Comté; S. Daucourt, Direction Régionale de l'Environnement, de l'Aménagement et du Logement de Franche-Comté (DREAL); A. David, Office National de l'Eau et des Milieux Aquatiques (ONEMA); A. Piot, Hôtel et lac de l'Abbaye, Grande-Rivière; owners of the pond Bachetey, Haute-Saône. Austria-M. Messner, Bezirkshauptmannschaft Reutte; municipalities of Grän and Nesselwängle, Tirol. Germany—G. Riegel, Regierungsbezirk Schwaben; K. Neugebauer, Regierungsbezirk Oberbayern; H. Lampartner, Regierungspräsidium Tübingen; B. Schmidt, Landratsamt Ravensburg; U. Weiland, Zweckverband Allgäuer Moorallianz; S. Socher, Bayerischen Landesamt für Umwelt in Augsburg; Naturpark Südschwarzwald; S. Rossiwal, Regierung von Oberbayern, U. Grabner, Starnberg; J. Kunsler, Bad Endorf; NSG Eggstätt-Hemhofer Seenplatte; B. Zimmermann, Regierungspräsidium Freiburg. We thank the Natural History Museum Fribourg (Switzerland) and the Fonds de recherche of the University of Fribourg (Switzerland, project number 516) for their logistic and financial support. N.A. is funded by an SNSF Ambizione research grant (PZ00P3_148224). We thank also two anonymous reviewers for their constructive comments, which helped us to improve the manuscript.

\section{References}

Alcala N, Streit D, Goudet J, Vuilleumier S (2013) Peak and persistent excess of genetic diversity following an abrupt migration increase. Genetics 193:953-971

Arrigo N, Buerki S, Sarr A, Guadagnuolo R, Kozlowski G (2011) Phylogenetics and phylogeography of the monocot genus Baldellia (Alismataceae): mediterranean refugia, suture zones and implications for conservation. Mol Phylogenet Evol 58:33-42 
Balao F, Casimiro-Soriguer R, García-Castaño JL, Terrab A, Talavera S (2015) Big thistle eats the little thistle: does unidirectional introgressive hybridization endanger the conservation of Onopordum hinojense? New Phytol 206:448-458

Barton NH (2001) The role of hybridization in evolution. Mol Ecol 10:551-568

Becker M, Gruenheit N, Steel M, Voelckel C, Deusch O, Heenan PB, McLenachan PA, Kardaisky O, Leigh JW, Lockhart PJ (2013) Hybridization may facilitate in situ survival of endemic species through periods of climate change. Nat Clim Change 3:1039-1043

Brown LE (1971) Natural hybridization and trend toward extinction in some relict texas toad populations. Southwest Nat 16:185-199

Buerkle CA (2005) Maximum-likelihood estimation of a hybrid index based on molecular markers. Mol Ecol Notes 5:684-687

Chapman MA, Burke JM (2007) Genetic divergence and hybrid speciation. Evolution 61-67:1773-1780

Chase WM, Hills HG (1991) Silica gel: an ideal material for field preservation of leaf samples for DNA studies. Taxon 40:215-220

Csilléry K, François O, Blum MGB (2012) abc: an R package for approximate Bayesian computation (ABC). Methods Ecol Evol 3:475-479

Delplancke M, Alvarez N, Benoit L, Espíndola A, Jolz HI, Neuenschwander S, Arrigo N (2012) Evolutionary history of almond tree domestication in the mediterranean basin. Mol Ecol 22:1092-1104

Dezhi F, Padgett D (2001) Genus Nuphar (Nymphaeaceae). Flora of China 6:115-116

Engler R, Randin C, Thuiller W, Dullinger S, Zimmermann A, Araùjo MB, Pearmann PB, Le Lay G, Piédallu C, Albert $\mathrm{CH}$ et al (2011) 21st century climate change threatens mountain flora unequally across Europe. Glob Change Biol 17:2330-2341

Excoffier L, Foll M, Petit R (2009) Genetic consequences of range expansions. Annu Rev Ecol Evol Syst 40:481-501

Fedorov AA (1974) Chromosome numbers of flowering plants. Academy of Natural Sciences of the USSR, Leningrad

Fitzpatrick B (2012) Estimating ancestry and heterozygosity of hybrids using molecular markers. BMC Evol Biol 12:131

Garnett ST, Olsen P, Butchart SHM, Hoffmann AA (2011) Did hybridization save the Norfolk Island boobook owl Ninox novaeseelandae undulata? Oryx 45:500-504

Garroway CJ, Bowman J, Cascaden TJ, Holloway GL, Mahan CG, Malcolm JR, Steele MA, Turner G, Wilson PJ (2010) Climate change induced hybridization in flying squirrels. Glob Change Biol 16:113-121

Gómez JM, González-Megías A, Lorite J, Abdelaziz M, Perfectti F (2015) The silent extinction: climate change and the potential hybridization-mediated extinction of endemic high-mountain plants. Biodivers Conserv 24:1843-1857

Hampe A, Jump AS (2011) Climate relicts: past, present, future. Annu Rev Ecol Evol 42:313-333

Hegarty MJ, Hiscock SJ (2005) Hybrid speciation in plants: new insights from molecular studies. New Phytol 165:411-423

Heslop-Harrison Y (1953) Nuphar intermedia Lebed., a presumed relict hybrid in Britain. Watsonia 3:7-25

Heslop-Harrison Y (1955) Nuphar Sm. J Ecol 43:342-364

Kabátova K, Vít P, Suda J (2014) Species boundaries and hybridization in central-European Nymphaea species inferred from genome size and morphometric data. Preslia 86:131-154

Käsermann Ch, Moser DM (1999) Merkblätter Artenschutz, Blütenpflanzen und Farne. Bern, Switzerland: Bundesamt für Umwelt, Wald und Landschaft (BUWAL)

Kozlowski G, Eggenberg S (2005) Vorkommen der Kleinen Teichrose Nuphar pumila und des Hybrids N. $x$ intermedia in der Schweiz. Bot Helv 115:125-136

Levin DA, Francisco-Ortega J, Jansen RK (1996) Hybridization and the extinction of rare plant species. Conserv Biol 10:10-16

López-Caamal A, Cano-Santana Z, Jiménez-Ramírez J, Ramírez-Rodríguez R, Tovar-Sánchez E (2014) Is the insular endemic Psidium socorrense (Myrtaceae) at risk of extinction through hybridization? Plant Syst Evol 300:1959-1972

Lozano FD, Moreno Saiz JC, Sainz Ollero H, Herbada DG, Rivero LM (2008) Lista roja de la flora vascular espanola. Conservation Vegetal, Madrid

Mallet J (2007) Hybrid speciation. Nature 446:279-283

Meusel H, Mühlberg H, Fuchs HP (1965) Nymphaeaceae. In: Hegi G, ed, Illustrierte Flora von Mitteleuropa. Band III. Teil 3, München edn. Carl Hanser, Germany

Muhlfeld CC, Kovach RP, Jones LA, Al-Chokhachy R, Boyer MC, Leary RF, Lowe WH, Luikart G, Allendorf FW (2014) Invasive hybridization in a threatened species is acceleratedby climate change. Nat Clim Change 4:620-624 
Neuenschwander S, Hospital F, Guillaume F, Goudet J (2008) Quantinemo: an individual-based program to simulate quantitative traits with explicit genetic architecture in a dynamic metapopulation. Bioinformatics 24:1552-1553

Nierbauer KU, Kanz B, Zizka G (2014) The widespread naturalisation of Nymphaea hybrids is masking the decline of wild-type Nymphaea alba in Hesse, Germany. Flora 209:122-130

Oberdorfer E (1977) Süddeutsche Pflanzengesellschaften. Teil I, Zweite edn. Gustav Fischer, Stuttgart

Ouborg NJ, Goodall-Copestake WP, Saumitou-Laprade P, Bonnin I, Epplen JT (2000) Novel polymorphic microsatellite loci isolated from the yellow waterlily, Nuphar lutea. Mol Ecol 9:497-498

Padgett DJ (1998) Phenetic distinction between the dwarf yellow water-lilies: Nuphar microphylla and $N$. pumila (Nymphaeaceae). Can J Bot 76:1755-1762

Padgett DJ (2007) A monograph of Nuphar (Nympheaceae). Rhodora 109:1-95

Padgett DJ, Les DH, Crow GE (1998) Evidence for the hybrid origin of Nuphar $\times$ rubrodisca (Nymphaeaceae). Am J Bot 85:1468-1476

Padgett DJ, Les DH, Crow GE (1999) Phylogenetic relationships in Nuphar (Nymphaeaceae): evidence from morphology, chloroplast DNA, and nuclear ribosomal DNA. Am J Bot 86:1316-1324

Padgett DJ, Shimoda M, Horky LA, Les DH (2002) Natural hybridization and the imperiled Nuphar of western Japan. Aquat Bot 72:161-174

Pajkovic M, Lappe S, Barman R, Parisod C, Neuenschwander S, Goudet J, Alvarez N, Guadagnuolo R, Felber F, Arrigo N (2014) Wheat alleles introgress into selfing wild relatives: empirical estimates from approximate Bayesian computation in Aegilops triuncialis. Mol Ecol 23:5089-5101

Preston CD, Croft JM (2001) Aquatic plants in Britain and Ireland. Harley Books, Colchester

Rhymer JM, Simberloff D (1996) Extinction by hybridization and introgression. Annu Rev Ecol Syst 27:83-109

Rieseberg RH (1997) Hybrid origins of plant species. Annu Rev Ecol Syst 28:359-389

Rieseberg RH, Baird SJE, Gardner KA (2000) Hybridization, introgression, and linkage evolution. Plant Mol Biol 42:205-224

Roweck H (1988) Ökologische Untersuchungen an Teichrosen. Archiv für Hydrobiologie. Stuttgart, Germany: E. Schweizerbart'sche Verlagsbuchhandlung, Supplementband. 81 Heft 2/3. Nägele u. Obermiller

Roweck H, Reinöhl H (1986) Zur verbreitung und systematischen abgrenzung der teichrosen Nuphar pumila und N. $\times$ intermedia in Baden-Württemberg. Veröffentlichungen Landesstelle Naturschutz BadenWürttemberg 61:81-151

Shiga T, Kadono Y (2007) Natural hybridization of the two Nuphar species in northern Japan: homoploid hybrid speciation in progress? Aquat Bot 86:123-131

Shiga T, Kadono Y (2008) Genetic relationships of Nuphar in central to western Japan as revealed by allozyme analysis. Aquat Bot 88:105-112

Theurillat JP, Guisan A (2001) Potential impact of climate change on vegetation in the European alps: a review. Clim Change 50:77-109

Thórsson AT, Pálson S, Lascoux M, Anamthawat-Jónson K (2010) Introgression and phylogeography of Betula nana (diploid), B. pubescens (tetraploid) and their triploid hybrids in Iceland inferred from cpDNA haplotype variation. J Biogeogr 37:2098-2110

Todesco M, Pascual MA, Owens OL, Ostevik KL, Moyers BT, Hübner S, Heredia SM, Hahn MA, Casseys C, Bock DG, Rieseberg LH (2016) Hybridization and extinction. Evol Appl. doi:10.1111/eva.12367

Vilà M, Weber E, D'Antonio CM (2000) Conservation implications of invasion by plant hybridization. Biol Invasions 2:207-217

Whitney KD, Ahern JR, Campbell LG, Albert LP, King MS (2010) Patterns of hybridization in plants. Perspect Plant Ecol Evol Syst 12:175-182

Wolf DE, Takebayashi N, Rieseberg LH (2001) Predicting the risk of extinction through hybridization. Conserv Biol 15:1039-1053

Woolbright SA, Whitham TG, Gering CA, Allan GJ, Bailey JK (2014) Climate relicts and their associated communities as natural ecology and evolution laboratories. Trends Ecol Evol 29:406-416

Yokogawa M, Shiga T, Kaneko S, Isagi Y (2012) Development of nuclear microsatellite markers for the critically endangered freshwater macrophyte, Nuphar submersa (Nymphaeaceae), and cross-species amplification in six additional Nuphar taxa. Conserv Genet Resour 4:295-298 